\title{
Innovative Reactive Distillation Process for the Sustainable Purification of Lactic Acid
}

\author{
Cristina González-Navarretea ${ }^{a}$ Eduardo Sánchez-Ramíreza , César Ramírez-Márqueza , \\ Salvador Hernández ${ }^{\mathrm{a}}$ Enrique Cossío-Vargas ${ }^{\mathrm{b}}$, Juan Gabriel Segovia-Hernández ${ }^{\mathrm{a}}$ *
}

a Universidad de Guanajuato, Campus Guanajuato, División de Ciencias Naturales y Exactas, Departamento de Ingeniería Química, Noria Alta S/N, Guanajuato, Guanajuato, México 36050

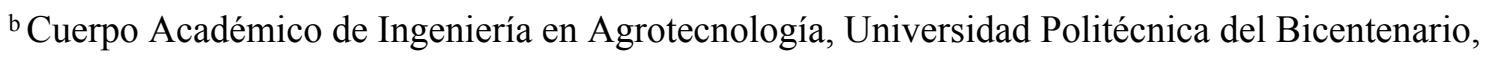
Carr. Silao-Romita Km 2, San Juan de los Durán, Silao de la Victoria, Guanajuato, México, 36283.

* Author to whom all correspondence should be addressed, E-mail: gsegovia@ugto.mx, Phone: (473) 7320006 Ext 1403.

\section{Supporting Information for Publication}

\author{
Total number of Pages: 17 \\ Total number of Figures: 2 \\ Total number of Tables: 4
}

\begin{tabular}{c|c} 
Content & Page No \\
\hline Sustainability Metrics & S2 \\
Economic Metric & S2 \\
Environmental Metric & S3 \\
Inherent Safety Metric & S5 \\
Controllability index calculation & S7 \\
Optimization Strategy and Objective Function & S9 \\
Normalization Procedure & S11 \\
Kinetic data & S12 \\
Binary Interaction Parameters & S12 \\
Composition, temperature, and pressure & S13 \\
References & S14 \\
\hline
\end{tabular}




\section{S.1. - Sustainability Metrics}

Sustainability can be viewed as a framework with targets to achieve economic, environmental, and inherent safety indexes, among others ${ }^{1-8}$. Furthermore, modification in the topology for the same process can also modify sustainability indexes ${ }^{2}$. Jiménez-Gonzalez et al. $^{3}$ propose clear mathematical strategies to evaluate those sustainability metrics. This work tries to analyze different topologies, based on a modification of the conventional intensified design, for the reactive distillation process for lactic acid purification and select the most promising ones according to metrics as proposed in the paper of Jiménez-Gonzalez et al. ${ }^{3}$.

\section{S.1.1 - Economic Metric}

All designs were compared using the total annual cost (TAC), which was calculated using the method published by Turton et al. ${ }^{4}$. A point that should be highlighted is that this methodology allows the calculation of the cost of equipment for a wide variety of sizes and flows (including the case study that is analyzed in this work).

The TAC approximation is described in equation $\mathrm{S} 1$.

$$
T A C=\frac{\sum_{i=1}^{n} C_{T M, i}}{r}+\sum_{j=1}^{n} C_{u t, j}
$$

The total module cost is calculated from equation S2.

$$
C_{T M}=1.18 \sum_{i=1}^{n} C_{B M, i}^{0}
$$

Where the term $C_{B M}^{0}$ represents the cost of the bare module, which reflects the direct and indirect costs for each unit. The term 1.18 depends on the type of chemical plant. If it is a plant that processes fluids, it is the indicated value. This term is calculated by equation S3.

$$
C_{B M}^{0}=C_{p} F_{B M}^{0}
$$

And, in most cases, $F_{B M}^{0}$ (bare module cost factor) is calculated by equation S4.

$$
F_{B M}^{0}=\left(B_{1}+B_{2} F_{M} F_{P}\right)
$$


The constants $\mathrm{B}_{1} \mathrm{y}_{2}$ for the bare modulus factor depend on the type of equipment and its description, e.g. pumps, vessels, and heat exchangers. That is, for vertical vessels, $\mathrm{B}_{1}$ is 2.25 and $\mathrm{B}_{2}$ is 1.82 and, on the other hand, for horizontal vessels, $\mathrm{B}_{1}$ is 1.49 and $\mathrm{B}_{2}$ is 1.52 .

The pressure factor $F_{p}$ is obtained from equation $\mathrm{S} 5$ :

$$
\log _{10} F_{p}=C_{1}+C_{2} \log _{10} P+C_{3}\left(\log _{10} P\right)^{2}
$$

For pressures $<5$ bar, $\mathrm{C}_{1}=\mathrm{C}_{2}=\mathrm{C}_{3}=0$. Pressure factors are always greater than unity. The values of constants in equation S5 for different equipment are given in Turton et al. ${ }^{4}$, where $C_{T M, i}$ represents the cost of capital of the plant, $\mathrm{r}$ the number of years of return on investment, $\mathrm{n}$ is the total number of individual units, $C_{u t, j}$ is the cost of services, $C_{B M, i}^{0}$ represents the cost of the bare module, $\mathrm{C}_{\mathrm{p}}$ is the purchase cost of the equipment under base conditions (carbon steel as construction material and ambient operating conditions), $F_{B M}^{0}$ is the cost factor of the bare module which contains all the adjustment factors, FM is the material factor, $F_{P}$ is the pressure factor, and, finally, $\mathrm{B}_{1}$ and $\mathrm{B}_{2}$ are factors that depend on the type of equipment.

The economic study performed considers 5 years as the recovery period. The plant is assumed to run 8,500 hours/year. Note that the costs of utilities used here are: high-pressure (HP) steam (42 bar, $254{ }^{\circ} \mathrm{C}, \$ 9.88 \mathrm{GJ}^{-1}$ ), medium-pressure (MP) steam (11 bar, $184{ }^{\circ} \mathrm{C}, \$ 8.22$ $\left.\mathrm{GJ}^{-1}\right)$, low-pressure (LP) steam $\left(6 \mathrm{bar}, 160^{\circ} \mathrm{C}, \$ 7.78 \mathrm{GJ}^{-1}\right)$, and cooling water $\left(\$ 0.72 \mathrm{GJ}^{-1}\right)^{4}$. In the case of reactive columns, the method indirectly estimates the catalyst costs for the reactive zone.

\section{S.1.2. - Environmental Metric}

Eco-Indicator 99 (EI99) is based on the life cycle assessment and the approach was proposed by Goedkoop and Spriensma ${ }^{6}$. EI99 is used to quantify the environmental impact due to the multiple activities performed in the process. This metric has already been tested in different scenarios in the state-of-the-art chemical professions ${ }^{7}$. For example, it has been reported to be applied in flowsheet optimization, in cooling system optimization ${ }^{8}$, and also in the optimal planning of biomass conversion systems ${ }^{9}$. Recently, it has been applied successfully in screening different alternatives with the lowest environmental impact, for example, in Vazquez-Castillo et al. ${ }^{10}$, and Torres-Vinces et al. ${ }^{11}$. The EI99 is calculated as follows: 


$$
E I 99=\sum_{b} \Sigma_{d} \Sigma_{k e K} \delta_{d} \omega_{d} \beta_{b} \alpha_{b, k}
$$

Where $\beta_{\mathrm{b}}$ represents the total amount of chemical $\mathrm{b}$ released per unit of reference flow due to direct emissions, $\alpha_{b, k}$ is the damage caused in category $k$ per unit of chemical $b$ released to the environment, $\omega_{\mathrm{d}}$ is a weighting factor for damage in category $\mathrm{d}$, and $\delta_{\mathrm{d}}$ is the normalization factor for damage of category $\mathrm{d}$. According to the importance of three major impact categories (human health, ecosystem quality, and resources depletion), the weighting for EI99 was specified as follows: damage to human health and damage to ecosystem quality were set equal in importance (i.e. both categories were equally weighted), while damage to resources was considered to be half of the importance for weighting. The impact categories and the values of these used in this study were taken from a previously reported work ${ }^{6}$. The scale of the values was chosen such that the value of 1 point is representative for a 1000th of the yearly environmental load of one average EU inhabitant. In this case study, the environmental load will be considered as generated by three materials: steel for building the columns, steam for heating, and electricity for pumping cooling water. The eco points for each category are presented in Table S1.

Table S1. Unit eco-indicator used to measure eco-indicator 99 in both case studies ${ }^{6}$.

\section{Steel Steam $\quad$ Electricity}

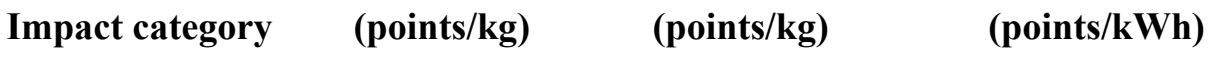

\begin{tabular}{cccc}
\hline Carcinogenic & $6.320 \mathrm{e}^{-03}$ & $1.180 \mathrm{e}^{-04}$ & $4.360 \mathrm{e}^{-04}$ \\
Climate change & $1.310 \mathrm{e}^{-02}$ & $1.600 \mathrm{e}^{-03}$ & $3.610 \mathrm{e}^{-06}$ \\
& $4.510 \mathrm{e}^{-04}$ & $1.130 \mathrm{e}^{-03}$ & $8.240 \mathrm{e}^{-04}$ \\
Ionizing radiation & & & \\
Ozone depletion & $4.550 \mathrm{e}^{-06}$ & $2.100 \mathrm{e}^{-06}$ & $1.210 \mathrm{e}^{-04}$ \\
Respiratory & $8.010 \mathrm{e}^{-02}$ & $7.870 \mathrm{e}^{-07}$ & $1.350 \mathrm{e}^{-06}$ \\
effects & & & \\
Acidification & $2.710 \mathrm{e}^{-03}$ & $1.210 \mathrm{e}^{-02}$ & $2.810 \mathrm{e}^{-04}$ \\
Ecotoxicity & $7.450 \mathrm{e}^{-02}$ & $2.800 \mathrm{e}^{-03}$ & $1.670 \mathrm{e}^{-04}$
\end{tabular}


Land Occupation
$3.730 \mathrm{e}-03$
$8.580 \mathrm{e}^{-05}$
$4.680 \mathrm{e}^{-04}$

Mineral extraction
$5.930 \mathrm{e}^{-02}$
$1.250 \mathrm{e}^{-02}$
$1.200 \mathrm{e}-03$
$7.420 \mathrm{e}-02$
$8.820 \mathrm{e}^{-06}$
$5.700 \mathrm{e}^{-06}$

\section{S.1.3. - Inherent Safety Metric}

Process safety is quantified by the individual risk (IR) index. The IR can be defined as the risk of injury or decease to a person in the vicinity of a hazard ${ }^{12}$. The main objective of this index is the estimation of likelihood affectation caused by the specific incident that occurs with a certain frequency. The IR does not depend on the number of people exposed. The mathematical expression for calculating individual risk is the following:

$$
I R=\sum f_{i} P_{x, y}
$$

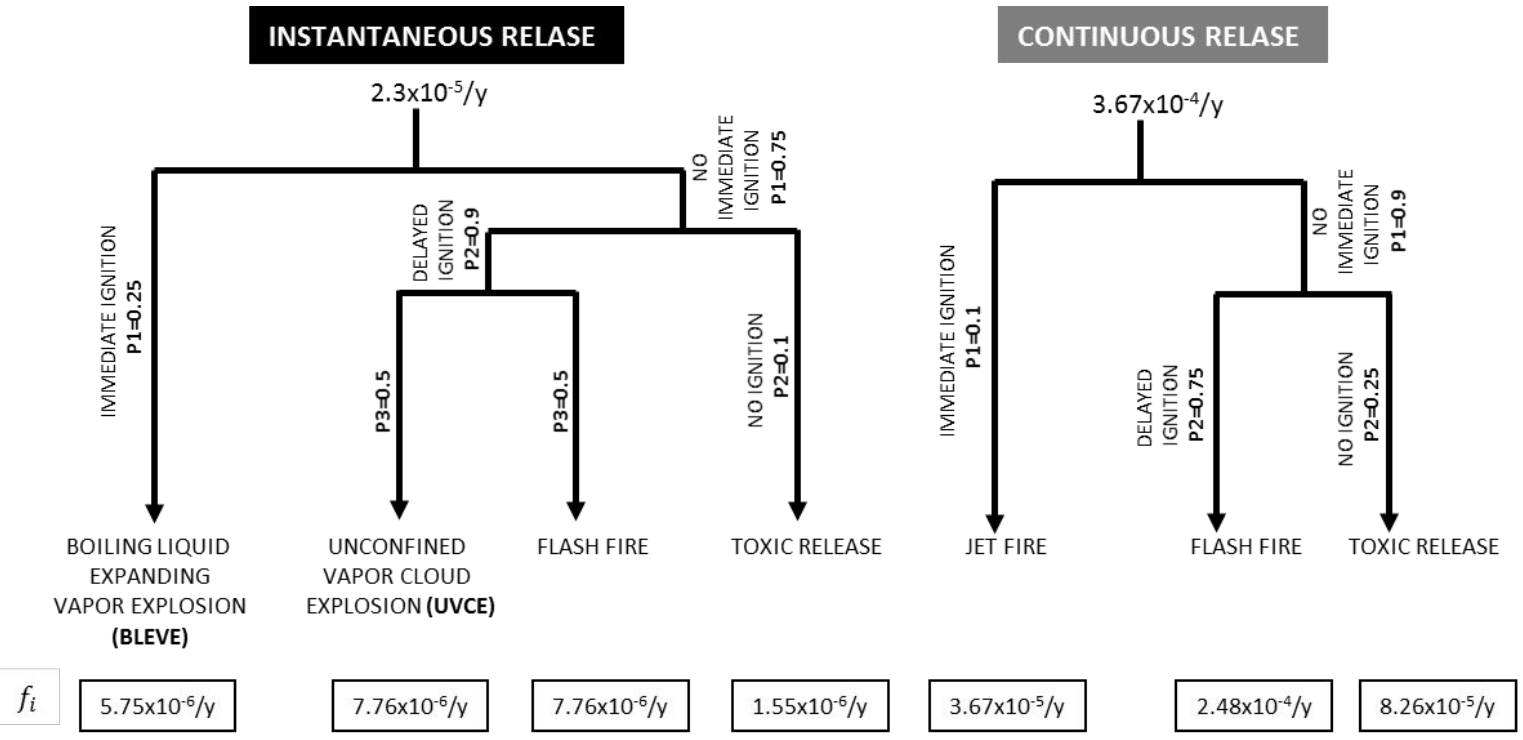

Figure S1. Possible accidents and frequencies that can happen in a process ${ }^{13}$.

Where $f_{i}$ is the occurrence frequency of incident $i$, whereas $P_{x, y}$ is the probability of injury or decease caused by the incident $I$ (See Figure S1). In this work, an irreversible injury (decease) is used, for which more data are recorded. The calculation of IR can be carried out through quantitative risk analysis (QRA), which is a methodology used to identify incidents and 
accidents and their consequences. The QRA starts with the identification of possible incidents. For distillation columns, continuous release and instantaneous release are identified. A continuous release is produced mainly by a rupture in a pipeline or partial rupture on a process vessel causing a leak. The instantaneous release consists of the total loss of matter from the process equipment originated by a catastrophic rupture of the vessel. These incidents were determined through hazard and operability study (HAZOP). The frequencies for each incident $\left(f_{i}\right)$ were taken according to the previously reported values by the American Institute of Chemical Engineers ${ }^{12}$ and using the event tree diagrams obtained with all probabilities of instantaneous and continuous incidents, along with their respective frequencies. Accordingly, instantaneous incidents are: boiling liquid expanding vapor explosion (BLEVE), unconfined vapor cloud explosion (UVCE), flash fire, and toxic release; whereas the continuous release incidents are: jet fire, flash fire, and toxic release.

Once the incidents have been identified, the probability $P_{x, y}$ can be calculated through a consequence assessment, which consists of determining the physical variables as the thermal radiation, the overpressure, and the concentration of the leak originated by incidents and their respective damages. The calculation of the physical variables was realized according to the equations reported by the Institute of Chemical Engineers ${ }^{12}$. The worst scenario was considered for calculating the dispersion, as well as a wind speed of $1.5 \mathrm{~m} / \mathrm{s}$ and atmospheric stability type $\mathrm{F}^{2,10}$.

The quantification of the damage caused by the physical variables of each incident is calculated through a vulnerability model commonly known as the probit model. In this work, the damage considered is death due to fires, explosions, and toxic releases. The probit models associated with deceases by thermal radiation $\left(\mathrm{t}_{\mathrm{e}} \mathrm{E}_{\mathrm{r}}\right)$ and overpressure due to explosions $\left(\mathrm{p}^{\circ}\right)$ are:

$$
\begin{aligned}
& Y=-14.9+2.56 \ln \left(\frac{t_{e} E_{r}^{\frac{4}{3}}}{10^{4}}\right) \\
& Y=-77.1+6.91 \ln \left(p^{0}\right)
\end{aligned}
$$


In this work, the calculation of the damage for toxic releases was carried out using the $\mathrm{LC}_{50}{ }^{12}$. Finally, the probability $P_{x, y}$ is calculated substituting the probit results into the following equation:

$$
P_{x, y}=0.5\left[1+\operatorname{erf}\left(\frac{Y-5}{\sqrt{2}}\right)\right]
$$

\section{S.1.4. - Controllability index calculation}

As a further study, the controllability of all the alternatives proposed in this work was evaluated. The controllability characteristics are evaluated using the condition number as an index. Singular value decomposition (SVD) of the relative gain matrix of the assessed design at a nominal point was used to get the condition number. To put it another way, when a design satisfies all constraints, the singular values are acquired before the condition number is calculated. The SVD is a numerical technique that was created to reduce the amount of computational error in massive matrix operations ${ }^{14}$. According to the following equation, the singular value decomposition of a matrix ( $\mathrm{K}$ in this case) results in three component matrices.

$$
K=U \Sigma V^{T}
$$

Where $\mathrm{K}$ is a $n \times m$ matrix, $\mathrm{U}$ is a $n \times n$ orthonormal matrix referred to as the "left singular vector," and V is a m x m diagonal of scalers referred to as the "singular values," and they are structured as follows: $\sigma 1>\sigma 2>\sigma 3 \ldots \sigma \mathrm{m}>0$. Both $\mathrm{U}$ and $\mathrm{V}$ consist of a basic coordinate rotation in terms of matrix operations. The SVD determines the rank and condition of a matrix and translates the strengths and weaknesses of a set of equations graphically in matrix operation.

The SVD is appealing and intriguing in terms of controllability because, when applied to a matrix that reflects the steady-state component of a multivariable process, the singular vectors and singular values have a very specific physic interpretation: the physical scaled steady-state sensitivity to changes of each process sensor in each of the controlled variables is represented by $\mathrm{K}$, the steady-state gain matrix.

The most precise coordinate system for visualizing the process sensors is $U$, the left singular vector. In other words, the first singular vector $\mathrm{U} 1$ represents the simplest direction in which 
the system must be altered, whereas U2 represents the second simplest direction, and so on. $\mathrm{V}$, the right singular vector, denotes the most precise coordinate system for visualizing the controlled variables, allowing us to determine the combination of control actions that will most likely have the greatest influence on the system.

The optimum decoupling gain of the open-loop process is provided by the diagonal of the singular values. The condition number of the gain matrix is a direct measure of the complexity of the decoupled multivariable control issue ${ }^{14}$. It is the ratio of the greatest singular to the smallest value.

The condition number is a ratio that measures the "condition" of a collection of equations by comparing the biggest and lowest single values.

$$
\gamma=\sigma_{\max } / \sigma_{\min }
$$

In terms of controllability, a high condition number suggests that satisfying the complete set of control objectives (regardless of the control method employed) will be inconvenient ${ }^{14}$. The condition number physically reflects the ratio of the system's maximum and least open-loop decoupled gains. A high condition number indicates that a system's relative sensitivity in one multivariable direction is low $^{14}$.

Each process design creates a relative gain matrix in a nominal state and the condition number of the relative gain matrix is determined in this study using an open-loop control policy. Each matrix's members are computed with a disturbance in the manipulated variable in mind (reflux ratio, reboiler heat duty, side stream flowrate, and so on). The amplitude of the perturbation was set at a $0.5 \%$ increase in the values of the altered variables compared to their nominal condition. These perturbations have a low enough influence that a first-order reaction following perturbation may be expected.

The step-change is applied to the controlled variable and divided by two to have the same range of variation in both closing and opening action in the control valves. This factor allows us to link the magnitude of change in the manipulated variable to the magnitude of change in the control valve, which can only vary between 0 and $100 \%$. This type of scaling achieves dimensionless standardization and modified variables at the same time; to do this, the term 
(0.5) $P$ has been inserted in equation $\mathrm{S} 12$. The relative gain matrix for the distillation sequences is represented by equation S13.

$$
\left[\begin{array}{lll}
K_{11} & K_{12} & K_{13} \\
K_{21} & K_{22} & K_{23} \\
K_{31} & K_{32} & K_{33}
\end{array}\right]=\left[\begin{array}{llll}
\frac{\left(x_{C 1}^{V_{1}}-x_{C 1}^{s p}\right)}{\frac{1}{2} p} & \frac{\left(x_{C 1}^{V_{2}}-x_{C 1}^{s p}\right)}{\frac{1}{2} p} & \frac{\left(x_{C 1}^{V_{3}}-x_{C 1}^{s p}\right)}{\frac{1}{2} p} \\
\frac{\left(x_{C 2}^{V_{1}}-x_{C 2}^{s p}\right)}{\frac{1}{2} p} & \frac{\left(x_{C 2}^{V_{2}}-x_{C 2}^{s p}\right)}{\frac{1}{2} p} & \frac{\left(x_{C 2}^{V_{3}}-x_{C 2}^{s p}\right)}{\frac{1}{2} p} \\
\frac{\left(x_{C 3}^{V 1}-x_{C 3}^{s p}\right)}{\frac{1}{2} p} & \frac{\left(x_{C 3}^{V_{2}}-x_{C 3}^{s p}\right)}{\frac{1}{2} p} & \frac{\left(x_{C 3}^{V_{3}}-x_{C 3}^{s p}\right)}{\frac{1}{2} p}
\end{array}\right]
$$

The elements on the left side of equation $\mathrm{S} 13, K_{\mathrm{ij}}$, are the relative gain matrix. Furthermore, the elements of the first row on the right side correspond to the differences among the mass purity of component $A$ in the nominal state $x_{A}^{s p}$, and the mass purities after disturbance $p . x_{A}^{V_{1}}$ is the mass purity of component $A$ after disturbance in manipulated variable $1, x_{A}^{V_{2}}$ is the mass purity of component $A$ after disturbance in manipulated variable $2, x_{A}^{V_{3}}$ is the mass purity of component $A$ after disturbance in manipulated variable 3.

\section{S.2. - Optimization Strategy and Objective Function}

The optimal design of intensified reactive distillation systems is a non-linear and multivariable problem, and the objective functions used as optimization criteria are generally non-convex with several local optimums. However, the task is complicated and is likely to fail to achieve convergence. In recent years, there has been an increased development and application of global optimization strategies in many areas of chemical engineering. Global optimization methods can be classified as deterministic or stochastic. The first class offers a guarantee of finding the global optimum of the objective function. However, strategies in this class often require high computational effort and, in some cases, problem reformulation is necessary as well. The use of rigorous design and thermodynamic models leads to very large non-convex models, which are very difficult to converge. Moreover, considering structural and design decisions, such as the existence of stages, columns, condensers, and reboilers, leads to the inclusion of integer variables further increasing the difficulty of solving the model. Finally, additional convergence problems are generated when discontinuous functions, such as complex cost functions, are introduced in the model. In this context, 
stochastic optimization methods are playing an important role because they are generally robust numerical tools that present a reasonable computational effort in the optimization of multivariable functions, they apply to unknown structure problems, they require only calculations of the objective function, and they can be used with all models without problem reformulation ${ }^{15}$.

To solve this case study, a metaheuristic optimization method based on the theory of natural selection was applied. This evolutionary method employs the classical Differential Evolution steps. However, its actions are improved through the Tabu List (TL) concept. Initially, this hybrid optimization algorithm was proposed because it $^{16}$ improves the computational efficiency of DE employing testing challenging phase equilibrium calculations followed by parameter estimation problems in dynamic systems known to have multiple minima. Later ${ }^{17}$, an adapted and improved DETL (See Figure S2) algorithm was applied to solve constrained multi-objective optimization problems, and the resulting algorithm is referred to as an integrated multi-objective differential evolution.

Operationally, the hybrid algorithm is coded in Visual Basic. Through dynamic data exchange (DDE), the numerical method generates input vectors that are evaluated in the process model (Aspen Plus). Then, the model evaluates the input vector and generates output vectors. After that, the hybrid method analyzes the input and output data and, according to the evolutionary nature of the algorithm, the process begins to iterate. The operational parameters for the stochastic method were: 120 individuals, 900 generations, $50 \%$ of the number of individuals as tabu list, 0.6 for the crossover and a taboo radius of $1 \times 10^{-6}$. These parameters were obtained from a tuning process in previous calculations. 

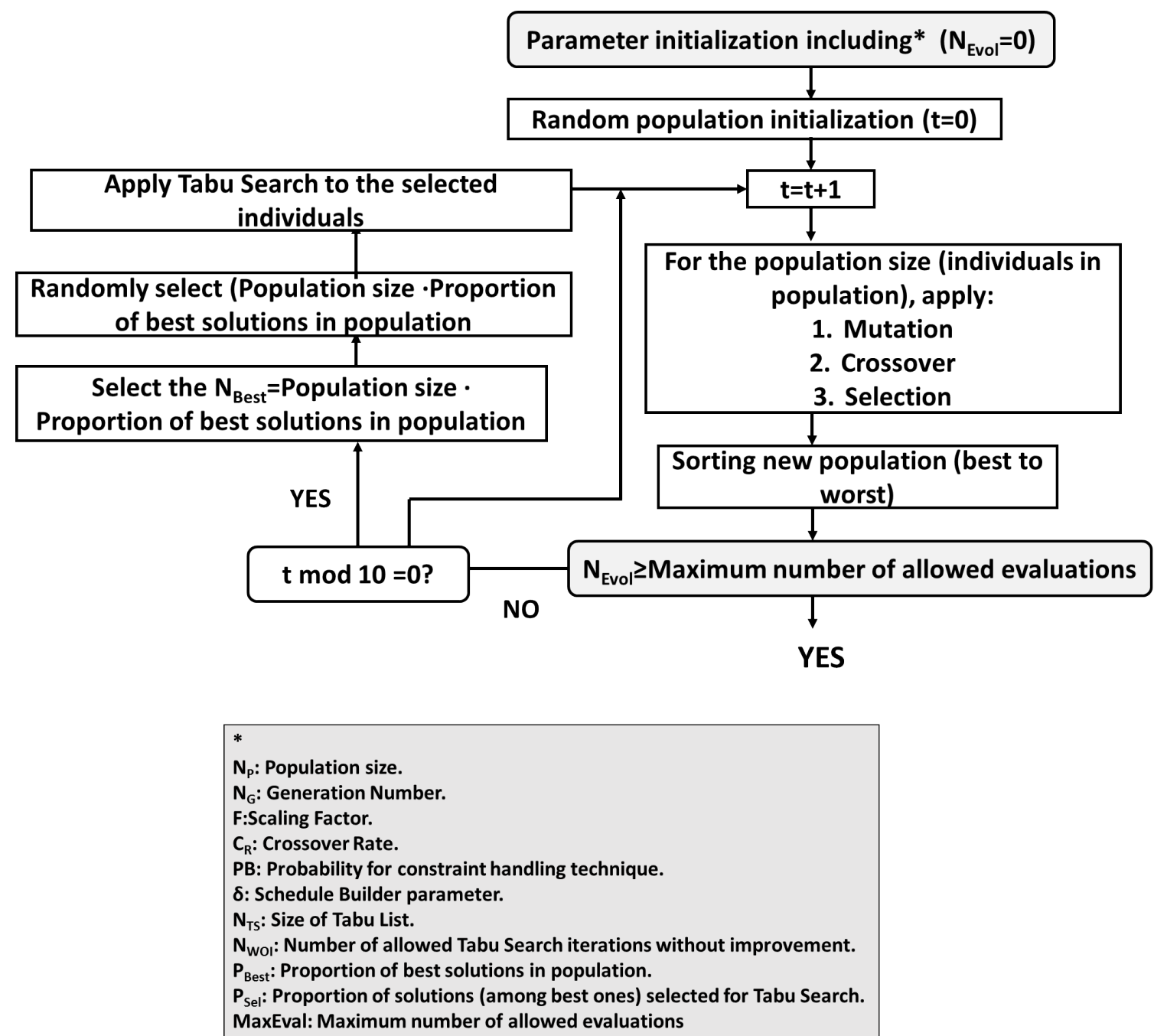

Figure S2. Flowchart of the DETL optimization algorithm ${ }^{18}$.

\section{S.2.1. - Normalization Procedure}

In general, it might be difficult to determine which sequence is optimal, in the overall notion of sustainability and green chemistry, when using a multi-objective optimization strategy. As a result, the goal of this research is to give a more comprehensive picture of the selection of the optimal design using a normalizing technique. The normalization of the goal functions (TAC, IR, and CN) allows the optimal sequence for the ideas of sustainability to be identified. According to Koski ${ }^{19}$, the goal functions should be normalized as follows:

$$
f_{i}(x)=\frac{F_{i}(x)-\min _{i}(x)}{\max F_{i}(x)-\min _{i}(x)} \quad i=\text { objective functions, } X \in N P
$$


When points in a plane or space are considered as vectors that start at the origin, the length of each one of these vectors may be determined to find the one that is closest to the minimization of both axes. The Euclidean distance may be computed in a generic fashion using the Pythagorean Theorem as follows:

$$
\text { Distance }=\sqrt{\sum_{i=1}^{i=N F} f_{i}^{2}}, N F=\text { Number of objective functions }
$$

Using this method of global selection criteria, the multiobjective optimization problem becomes the optimization of a scalar for the selection of the best solution. The benefit of using normalization is that it shows us how far is the optimum of an objective function of a sequence, concerning the optimum of the same objective function of another sequence. That is, how far we are from the ideals of a sustainable process.

\section{S.3. - Kinetic data}

Table S2. Kinetic data ${ }^{20}$.

\begin{tabular}{lc}
\hline \multicolumn{1}{c}{ Reaction } & Kinetic Model \\
\hline Methyl & $r=m_{\text {cat }}\left(k_{f} a_{A C L} a_{M E O H}-K_{r} a_{\text {METIL LACTATO }} a_{H_{2} O}\right)$ \\
& $k_{f}=2.98 \times 10^{4} \exp \left(-\frac{51300}{R T}\right)$ \\
& $k_{r}=2.74 \times 10^{2} \exp \left(-\frac{47200}{R T}\right)$ \\
\hline Dilactate & $r=m_{c a t}\left(k_{f} x_{A C L} a_{A C L}-K_{r} x_{L 2} x_{H_{2} O}\right)$ \\
& $k_{f}=1.1 \times 10 \exp \left(-\frac{52000}{R T}\right)$ \\
& $k_{r}=5.54 \times 10 \exp \left(-\frac{52000}{R T}\right)$ \\
\hline Trilactate & $r=m_{c a t}\left(k_{f} x_{L 2} a_{A C L}-K_{r} x_{L 3} x_{H_{2} O} O\right)$ \\
$k_{f}=4.53 \times 10^{-4} \exp \left(-\frac{50800}{R T}\right)$ \\
$k_{r}=2.28 \times 10 \exp \left(-\frac{50800}{R T}\right)$
\end{tabular}

\section{S.4. - Binary Interaction Parameters}

Table S3. Binary interaction parameters for UNIQUAC model $\left({ }^{\circ} \mathrm{C}\right)^{20}$. 


\begin{tabular}{|c|c|c|c|c|c|c|c|c|c|c|}
\hline $\begin{array}{l}\text { Compone } \\
\text { nt i } \\
\text { Compone } \\
\text { nt j } \\
\text { Property u }\end{array}$ & $\begin{array}{l}\text { LACTI } \\
\text { C } \\
\text { WATE } \\
\text { R } \\
\text { iits }\end{array}$ & $\begin{array}{l}\text { METHA } \\
\text { NOL } \\
\text { WATER }\end{array}$ & $\begin{array}{l}\text { WATER } \\
\text { SUCCI }\end{array}$ & $\begin{array}{l}\text { LACTIC } \\
\text { METHA } \\
\text { NOL }\end{array}$ & $\begin{array}{l}\text { LACTIC } \\
\text { METHY } \\
\text { L }\end{array}$ & $\begin{array}{l}\text { LACTIC } \\
\text { DILACT } \\
\text { AT }\end{array}$ & $\begin{array}{l}\text { LACTIC } \\
\text { TRILAC } \\
\text { TA }\end{array}$ & $\begin{array}{l}\text { LACTIC } \\
\text { SUCCI }\end{array}$ & $\begin{array}{l}\text { METHA } \\
\text { NOL } \\
\text { METHYL }\end{array}$ & $\begin{array}{l}\text { METHA } \\
\text { NOL } \\
\text { DILACT } \\
\text { AT }\end{array}$ \\
\hline AIJ & 0 & -1.0662 & 0 & 0 & 0 & 0 & 0 & 0 & 0 & 0 \\
\hline AJI & 0 & 0.6437 & 0 & 0 & 0 & 0 & 0 & 0 & 0 & 0 \\
\hline BIJ & 357.47 & 432.8785 & 84.863 & $\begin{array}{r}452.35478 \\
1\end{array}$ & $\begin{array}{r}- \\
288.3542 \\
38\end{array}$ & $\begin{array}{r}24.52948 \\
57\end{array}$ & $\begin{array}{r}74.21735 \\
09\end{array}$ & $\begin{array}{r}255.9867 \\
45\end{array}$ & $\begin{array}{r}- \\
7.5249021 \\
3\end{array}$ & 194.43041 \\
\hline BJI & -499.38 & -322.1312 & -8.6705 & $\begin{array}{r}- \\
1040.7581 \\
5\end{array}$ & $\begin{array}{r}208.3880 \\
98\end{array}$ & $\begin{array}{r}- \\
49.38615 \\
32\end{array}$ & $\begin{array}{r}- \\
96.47288 \\
08\end{array}$ & $\begin{array}{r}- \\
368.4693 \\
1\end{array}$ & $\begin{array}{r}- \\
41.366739 \\
1\end{array}$ & $\begin{array}{r}152.29492 \\
4\end{array}$ \\
\hline CIJ & 0 & 0 & 0 & 0 & 0 & 0 & 0 & 0 & 0 & 0 \\
\hline CJI & 0 & 0 & 0 & 0 & 0 & 0 & 0 & 0 & 0 & 0 \\
\hline DIJ & 0 & 0 & 0 & 0 & 0 & 0 & 0 & 0 & 0 & 0 \\
\hline DJI & 0 & 0 & 0 & 0 & 0 & 0 & 0 & 0 & 0 & 0 \\
\hline EIJ & 0 & 0 & 0 & 0 & 0 & 0 & 0 & 0 & 0 & 0 \\
\hline EJI & 0 & 0 & 0 & 0 & 0 & 0 & 0 & 0 & 0 & 0 \\
\hline
\end{tabular}

\begin{tabular}{|c|c|c|c|c|c|c|c|c|c|}
\hline $\begin{array}{l}\text { Compone } \\
\text { nt i } \\
\text { Compone } \\
\text { nt j }\end{array}$ & $\begin{array}{l}\text { METH } \\
\text { YL } \\
\text { WATE } \\
\text { R }\end{array}$ & $\begin{array}{l}\text { METHYL } \\
\text { DILACT } \\
\text { AT }\end{array}$ & $\begin{array}{l}\text { METHY } \\
\text { L } \\
\text { TRILAC } \\
\text { TA }\end{array}$ & METHYL & $\begin{array}{l}\text { WATER } \\
\text { DILACT } \\
\text { AT }\end{array}$ & $\begin{array}{l}\text { WATER } \\
\text { TRILAC } \\
\text { TA }\end{array}$ & $\begin{array}{l}\text { DILACT } \\
\text { AT } \\
\text { TRILAC } \\
\text { TA }\end{array}$ & $\begin{array}{l}\text { DILACT } \\
\text { AT } \\
\text { SUCCI }\end{array}$ & $\begin{array}{l}\text { TRILACT } \\
\text { A } \\
\text { SUCCI }\end{array}$ \\
\hline \multicolumn{10}{|c|}{ Property units } \\
\hline AIJ & 0 & 0 & 0 & 0 & 0 & 0 & 0 & 0 & 0 \\
\hline AJI & 0 & 0 & 0 & 0 & 0 & 0 & 0 & 0 & 0 \\
\hline BIJ & 217.487 & 298.30837 & 127.102 & $\begin{array}{r}417.61366 \\
7\end{array}$ & $\begin{array}{r}513.0071 \\
45\end{array}$ & $\begin{array}{r}415.0286 \\
29\end{array}$ & $\begin{array}{r}28.50522 \\
24\end{array}$ & $\begin{array}{r}234.4790 \\
42\end{array}$ & $\begin{array}{r}30.301504 \\
1\end{array}$ \\
\hline BJI & -393.07 & -479.58 & -156.67 & $\begin{array}{r}- \\
835.56505 \\
7\end{array}$ & $\begin{array}{r}272.2206 \\
97\end{array}$ & $\begin{array}{r}235.8390 \\
84\end{array}$ & $\begin{array}{r}- \\
5.523813 \\
86\end{array}$ & $\begin{array}{r}- \\
325.5096 \\
3\end{array}$ & $\begin{array}{r}91.452688 \\
2\end{array}$ \\
\hline CIJ & 0 & 0 & 0 & 0 & 0 & 0 & 0 & 0 & 0 \\
\hline CJI & 0 & 0 & 0 & 0 & 0 & 0 & 0 & 0 & 0 \\
\hline DIJ & 0 & 0 & 0 & 0 & 0 & 0 & 0 & 0 & 0 \\
\hline DJI & 0 & 0 & 0 & 0 & 0 & 0 & 0 & 0 & 0 \\
\hline EIJ & 0 & 0 & 0 & 0 & 0 & 0 & 0 & 0 & 0 \\
\hline EJI & 0 & 0 & 0 & 0 & 0 & 0 & 0 & 0 & 0 \\
\hline
\end{tabular}

\section{S.5. - Composition, temperature, and pressure.}

Table S4. Composition, temperature, and pressure.

\begin{tabular}{lrrrrrrrrrrr} 
& $\mathbf{1}$ & $\mathbf{2}$ & $\mathbf{3}$ & $\mathbf{4}$ & $\mathbf{5}$ & $\mathbf{6}$ & $\mathbf{7}$ & $\mathbf{8}$ \\
\hline Mass Frac & & & & & & & & & & & \\
LACTIC & $4.452 \mathrm{E}-31$ & $7.144 \mathrm{E}-01$ & $2.870 \mathrm{E}-01$ & $3.651 \mathrm{E}-01$ & $3.329 \mathrm{E}-08$ & & 0 & $1.555 \mathrm{E}-31$ & $9.091 \mathrm{E}-01$ & \\
METHANOL & 0 & 0 & $1.180 \mathrm{E}-01$ & $5.051 \mathrm{E}-01$ & $4.307 \mathrm{E}-19$ & $9.891 \mathrm{E}-01$ & $9.630 \mathrm{E}-01$ & $8.344 \mathrm{E}-09$ & $9.999 \mathrm{E}-01$ & $7.171 \mathrm{E}-12$ \\
METHYL & 0 & 0 & $4.004 \mathrm{E}-03$ & $2.077 \mathrm{E}-03$ & $2.915 \mathrm{E}-17$ & 0 & $8.400 \mathrm{E}-20$ & $1.635 \mathrm{E}-03$ & 0 & 0 \\
WATER & $1.000 \mathrm{E}+00$ & $1.657 \mathrm{E}-01$ & $5.819 \mathrm{E}-01$ & $1.236 \mathrm{E}-01$ & $9.780 \mathrm{E}-16$ & $1.091 \mathrm{E}-02$ & $3.600 \mathrm{E}-02$ & $8.921 \mathrm{E}-02$ & $1.000 \mathrm{E}-04$ & $1.000 \mathrm{E}+00$ \\
DILACTAT & 0 & 0 & $9.058 \mathrm{E}-03$ & $4.163 \mathrm{E}-03$ & $1.329 \mathrm{E}-12$ & 0 & $9.646 \mathrm{E}-26$ & $6.314 \mathrm{E}-05$ & \\
TRILACTA & 0 & 0 & $1.019 \mathrm{E}-10$ & $1.353 \mathrm{E}-15$ & $3.042 \mathrm{E}-10$ & 0 & $8.515 \mathrm{E}-37$ & 0
\end{tabular}




\begin{tabular}{|c|c|c|c|c|c|c|c|c|c|c|}
\hline SUCCI & $1.521 \mathrm{E}-45$ & $1.200 \mathrm{E}-01$ & $4.664 \mathrm{E}-08$ & $1.473 \mathrm{E}-08$ & $1.000 \mathrm{E}+00$ & 0 & $1.161 \mathrm{E}-28$ & $3.842 \mathrm{E}-08$ & 0 & 0 \\
\hline $\begin{array}{l}\text { Total Flow } \\
(\mathrm{kg} / \mathrm{hr})\end{array}$ & 728.04 & 527.089 & 73.11 & 1071.249 & 62.70538 & 1271.33 & 1858.9 & 411.2 & 533.78 & 85.09783 \\
\hline $\begin{array}{l}\text { Temperature } \\
\left({ }^{\circ} \mathrm{C}\right)\end{array}$ & 59.24254 & 74.56646 & 101.2122 & 70.51244 & 170.486 & 64.8348 & 67.78706 & 194.3389 & 64.53743 & 100.0178 \\
\hline Pressure (bar) & 0.1915212 & 0.4599 & 1.01325 & 0.00303975 & 0.00303975 & 1.01325 & 1.01325 & 1.01325 & 1.01325 & 1.01325 \\
\hline
\end{tabular}

\section{S.6. - References}

(1) Geissdoerfer, M.; Savaget, P.; Bocken, N. M. P.; Hultink, E. J. The Circular Economy - A New Sustainability Paradigm? J. Clean. Prod. 2017, 143, 757-768. https://doi.org/10.1016/j.jclepro.2016.12.048.

(2) Sánchez-Ramírez, E.; Quiroz-Ramírez, J. J.; Hernández, S.; Segovia Hernández, J. G.; Contreras-Zarazúa, G.; Ramírez-Márquez, C. Synthesis, Design and Optimization of Alternatives to Purify 2, 3-Butanediol Considering Economic, Environmental and Safety Issues. Sustain. Prod. Consum. 2019, 17, 282-295. https://doi.org/10.1016/j.spc.2018.11.011.

(3) Jiménez-González, C.; Constable, D. J. C.; Ponder, C. S. Evaluating the "Greenness" of Chemical Processes and Products in the Pharmaceutical Industry - A Green Metrics Primer. Chem. Soc. Rev. 2012, 41 (4), 1485-1498. https://doi.org/10.1039/c1cs15215g.

(4) Turton, R. Analysis, Synthesis and Design of Chemical Process, Fourth Edi.; Prentice Hall, 2001; Vol. 40.

(5) Luyben, W. L. Principles and Case Studies of Simultaneous Design; John Wiley \& Sons, Inc.: Hoboken, NJ, USA, 2011. https://doi.org/10.1002/9781118001653.

(6) Goedkoop, M., \& Spriensma, R. Eco-Indicator 99 Manual for Designers. $P R e^{\prime}$ Consult. Amersfoort, Netherlands. 2000, No. October.

(7) Guille, G.; Pennsyl, V.; Caballero, A. Application of Life Cycle Assessment to the Structural Optimization of Process Flowsheets. 2008, 777-789.

(8) Gebreslassie, B. H.; Guillén-Gosálbez, G.; Jiménez, L.; Boer, D. Design of Environmentally Conscious Absorption Cooling Systems via Multi-Objective Optimization and Life Cycle Assessment. Appl. Energy 2009, 86 (9), 1712-1722. 
https://doi.org/10.1016/j.apenergy.2008.11.019.

(9) Santibañez-Aguilar, J. E.; González-Campos, J. B.; Ponce-Ortega, J. M.; SernaGonzález, M.; El-Halwagi, M. M. Optimal Planning of a Biomass Conversion System Considering Economic and Environmental Aspects. Ind. Eng. Chem. Res. 2011, 50 (14), 8558-8570. https://doi.org/10.1021/ie102195g.

(10) Vázquez-Castillo, J. A.; Contreras-Zarazúa, G.; Segovia-Hernández, J. G.; Kiss, A. A. Optimally Designed Reactive Distillation Processes for Eco-Efficient Production of Ethyl Levulinate. J. Chem. Technol. Biotechnol. 2019, 94 (7), 2131-2140. https://doi.org/10.1002/jctb.6033.

(11) Torres-Vinces, L.; Contreras-Zarazua, G.; Huerta-Rosas, B.; Sánchez-Ramírez, E.; Segovia-Hernández, J. G. Methyl Ethyl Ketone Production through an Intensified Process. Chem. Eng. Technol. 2020, 43 (7), 1433-1441. https://doi.org/10.1002/ceat.201900664.

(12) Freeman, R. A. CCPS Guidelines for Chemical Process Quantitative Risk Analysis. Plant/Operations Prog. 1990, 9 (4), 231-235. https://doi.org/10.1002/prsb.720090409.

(13) Koski, J. Defectiveness of Weighting Method in Multicriterion Optimization of Structures. Commun. Numer. Methods Eng. 1985, 1 (6), 333-337. https://doi.org/10.1002/cnm.1630010613.

(14) Moore, C. Application of Singular Value Decomposition to The Design, Analysis, and Control of Industrial Processes. Am. Control Conf. 1986, 643-650.

(15) Teh, Y. S.; Rangaiah, G. P. Tabu Search for Global Optimization of Continuous Functions with Application to Phase Equilibrium Calculations. Comput. Chem. Eng. 2003, 27 (11), 1665-1679. https://doi.org/10.1016/S0098-1354(03)00134-0.

(16) Srinivas, M.; Rangaiah, G. P. Differential Evolution with Tabu List for Global Optimization and Its Application to Phase Equilibrium and Parameter Estimation Problems. Ind. Eng. Chem. Res. 2007, 46 (10), 3410-3421. https://doi.org/10.1021/ie0612459.

(17) Sharma, S.; Rangaiah, G. P. An Improved Multi-Objective Differential Evolution with a Termination Criterion for Optimizing Chemical Processes. Comput. Chem. Eng. 2013, 56, 155-173. https://doi.org/10.1016/j.compchemeng.2013.05.004.

(18) Ponsich, A.; Coello Coello, C. A. A Hybrid Differential Evolution - Tabu Search 
Algorithm for the Solution of Job-Shop Scheduling Problems. Appl. Soft Comput. J. 2013, 13 (1), 462-474. https://doi.org/10.1016/j.asoc.2012.07.034.

(19) Koski, J. Defectiveness of Weighting Method in Multicriterion Optimization of Structures. Commun. Numer. Methods Eng. 1985, 1 (6), 333-337. https://doi.org/10.1002/cnm.1630010613.

(20) Kim, S. Y.; Kim, D. M.; Lee, B. Process Simulation for the Recovery of Lactic Acid Using Thermally Coupled Distillation Columns to Mitigate the Remixing Effect. Korean J. Chem. Eng. 2017, 34 (5), 1310-1318. https://doi.org/10.1007/s11814-0170009-1. 


\section{References}

(1) Goedkoop, M., \& Spriensma, R. Eco-Indicator 99 Manual for Designers. $P R e^{\prime}$ Consult. Amersfoort, Netherlands. 2000, No. October.

(2) Kim, S. Y.; Kim, D. M.; Lee, B. Process Simulation for the Recovery of Lactic Acid Using Thermally Coupled Distillation Columns to Mitigate the Remixing Effect. Korean J. Chem. Eng. 2017, 34 (5), 1310-1318. https://doi.org/10.1007/s11814-017-0009-1. 